\title{
The Relationships between Leader Creativity Expectations, Intrinsic Motivation, and Creative Performance
}

\author{
Muhammad Shahnawaz \\ Adil $^{1}$
}

Kamal Bin Ab Hamid
COB-School of Business Management, Universiti Utara Malaysia (UUM), 06010 Sintok, Kedah Darul Aman, Malaysia

COB-School of Business Management, Universiti Utara Malaysia (UUM), 06010 Sintok, Kedah Darul Aman, Malaysia

\author{
Article History \\ Received 2019-03-01 \\ Accepted 2019-03-02 \\ Published 2019-03-03
}

Keywords

Leader Creativity Expectations,

Intrinsic Motivation,

Creative Performance

How to cite?

Adil, M. S., \& Hamid, K. B. A.

(2019). The Relationships between Leader

Creativity Expectations, Intrinsic

Motivation, and Creative Performance.

SEISENSE Journal of Management,

2(2), 58-68. doi:

bttps:// doi.org/10.33215/sjom.v2i2.123

Copyright (C) 2019 The Author(s)

\section{(cc) BY}

Objective - The objectives of this conceptual paper are two folds: to propose and argue a) the direct relationship between leader creativity expectations and creative performance; and b) the mediating role of intrinsic motivation between leader creativity expectations and creative performance.

Design - Drawing upon Pygmalion effect, Herzberg's twofactor theory of motivation, and componential theory of creativity, two propositions are suggested.

Findings - It is proposed that there will be a positive relationship between leader creativity expectations and creative performance. In addition, the authors also make the case that intrinsic motivation will mediate the relationship between leader creativity expectations and creative performance.

Originality - The significant original contribution of this article is that it suggests a theoretical relationship of Pygmalion effect with Herzberg's two-factor theory of motivation and componential theory of creativity to propose a new conceptual framework. In addition, this paper extends our knowledge regarding the pertinent role of leader creativity expectations in stimulating divergent thinking process of people in the workplace.

Policy Implications - This article attempts to provide a clear guideline to both practitioners and academicians to better explore the relationship between expectations and employee creativity. The proposed framework may be applied in various social contexts such as healthcare, education, creative advertising, research and development, hospitality and new business incubation.

${ }^{1}$ Corresponding author's email address: adil.s@iuk.edu.pk 


\section{Introduction}

In the 21 st century, employee creativity has been recognized as the most important leadership quality (Carr, 2010). Due to hyper-competition, it is increasingly becoming very difficult and challenging for business leaders and managers to gain and sustain their competitive advantage (D'Aveni \& Gunther, 1994). In fact, business organizations as well as educational establishments ought to induct highly creative people who could contribute far much better than a common employee in gaining and sustaining competitive advantage. The literature on creativity has suggested that there is a much-closed relationship between leadership variables and employee creative performance. These variables are generally characterized as contextual factors or boundary conditions. One of these boundary conditions is the leader's self-expectations of creativity from his/her subordinates. A very little is known about this relationship both in terms of theory as well as empirical examinations.

Therefore, the main idea of this conceptual paper is to propose and argue a direct relationship between leader creativity expectations and creative performance. Moreover, it also attempts to extend knowledge about the mediating effect of intrinsic motivation between leader creativity expectations and creative performance.

This paper is organized in the following way. Firstly it provides various definitions and frequently-used conceptualization of creativity. It then follows to describe the Pygmalion effect in order to establish its relationship with creative performance to suggest our first proposition. Later, the indirect effect of intrinsic motivation for the relationship between leader creativity expectations and creative performance is examined in light of Herzberg's two-factor theory and componential theory of creativity. It leads to suggest our second proposition. Finally, this paper provides a synthesis of the measurement of creative performance and leader creativity expectations.

\section{Definitions of Creativity}

The literature on creativity has stated numerous definitions of creativity. For instance, Guilford (1950) argued that "The creative person has novel ideas. The degree of novelty of which the person is capable, or which he habitually exhibits... can be tested in terms of the frequency of uncommon, yet acceptable, responses to items" (p. 452). Similarly, Ochse (1990) described that "Creativity involves bringing something into being that is Original (new, unusual, novel, unexpected) and also Valuable (useful, good, adaptive, appropriate)" (p. 2). Anderson (1992) argued that "Creativity is nothing more than going beyond the current boundaries, whether those are boundaries of technology, knowledge, social norms or beliefs" (p. 41).

Besides, a few authors have defined creativity in terms of generating novel and useful ideas. For instance, creativity refers to "The production of novel and useful ideas by an individual or small group of individuals working together" (Amabile, 1988, p. 126). In other words, "Creative thought or behavior must be both novel-original and useful-adaptive" (Feist, 1998, p. 290). Creativity is "...the ability to produce work that is both novels (i.e., original, unexpected) and appropriate (i.e., useful, adaptive concerning task constraints)" (Sternberg \& Lubart, 1999, p. 3). More recently, Ma (2009) noted that creativity denotes "... the ability to reorganize the available knowledge, information, cues, facts and/or skills in a person's reservoir to generate new ideas or useful solutions" (p. 39). Likewise, there are some authors who have listed down the various definition of creativity in one paper such as 25 interpretations of creativity in Morgan (1953).

Considering the fact that there are numerous interpretations and definitions of the word 'creativity' in the literature, it is necessary to describe the proper conceptualization of creativity in any empirical investigation. Some of the widely-used conceptualizations of creativity are discussed below. 


\section{Conceptualizations of Creativity}

Creativity has been conceptualized in different ways. For instance, creativity is an outcome in the form of a creative product; creativity is a multilevel phenomenon largely based on a 'sense-making' approach (Drazin, Glynn, \& Kazanjian, 1999); creativity reflects human positive and negative emotions (called 'affects') who tend to experience 'timelessness' in organizations (Mainemelis, 2001); creativity may be conceptualized into four types based on problem types and drivers of creative work engagement i.e. expected creativity, proactive creativity, responsive creativity, and contributory creativity (Unsworth, 2001); creativity is a social network which involves structural bridge having strong and weak ties of social relationship (Perry-Smith \& Shalley, 2003).

Besides, creativity has also been conceptualized as a cognitive behavior of individuals (Amabile, 1983; Csikszentmihalyi, 1996, Drazin et al., 1999) which involves a series of iterative processes. These processes tend to incite divergent thinking of an individual leading to a novel and useful solution of a problem in question (Runco \& Acar, 2012). Firstly, Wallas (1926) introduced four stages of a creative process i.e. "preparation, incubation, illumination (and its accompaniments), and verification" (p. 10). However, these four stages were further classified into five stages i.e. "preparation; incubation; intimation; illumination; verification" (Sadler-Smith, 2015, p. 342). Moreover, Policastro (1995) added 'creative intuition' between 'incubation' and 'illumination' phases of creative performance.

The componential theory of creativity (Amabile, 1983) describes three components of employee creative behavior namely, expertise, creative-thinking skills, and intrinsic motivation (Figure 1). According to this theory of creativity, expertise denotes the technical, procedural, and intellectual knowledge one possesses whereas, creative-thinking skills determine the extent to which an individual attempt to think imaginatively and flexible. Finally, unlike extrinsic motivation, intrinsic motivation is the actual inner passion of the individual to solve a problem in question.

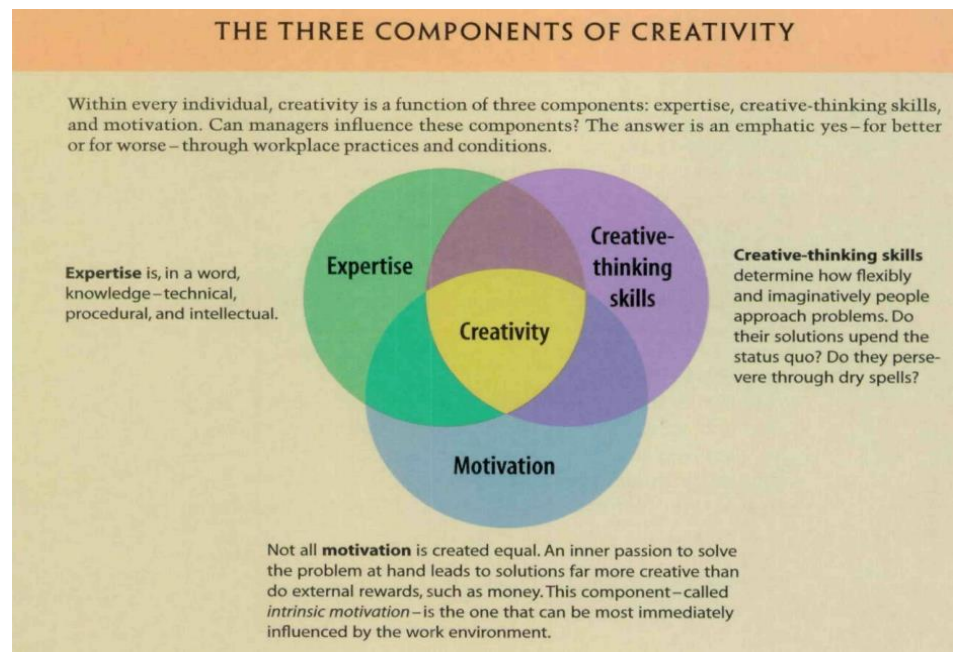

Figure 1 - Componential Theory of Creativity

Source: Amabile (1998, p. 78)

Recently, Amabile and Pratt (2016) upgraded the componential theory of creativity into a dynamic componential model of creativity (Figure 2) by developing a holistic framework of the individual, team, and organizational creativity and innovation. They added that although expertise, creative-thinking skills, and intrinsic motivation are very important, there are some other very important boundary conditions which have substantial effects on individual, team, and organizational creativity and innovation. These conditions include work orientation, meaningful work, and effect (i.e. emotions). To conclude, it is quite imperative to 
concentrate on various creative processes which may result in frequent mistakes as well as disappointments (Watson, 2018).

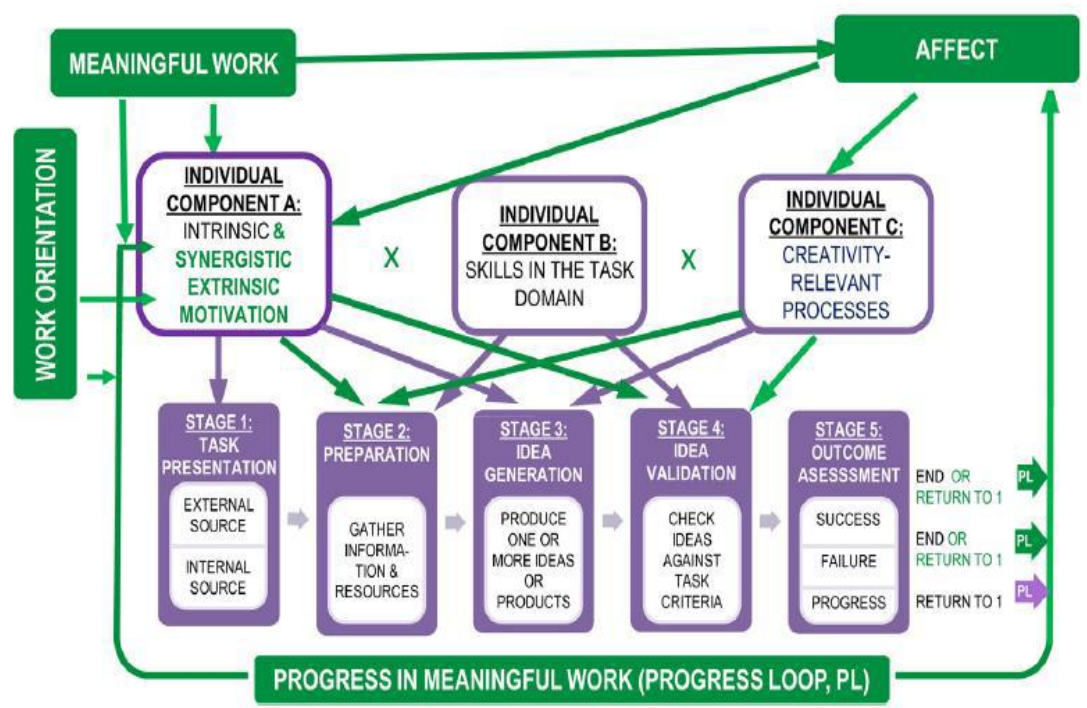

Figure 2 - Dynamic Componential Model of Creativity

Source: Amabile and Pratt (2016, p. 164)

\section{Pygmalion Effect and Leader Creativity Expectations}

Figure 3 illustrates the Pygmalion effect (Eden, 1984; Eden et al., 2000) holds that "if one expects more one gets more" (Carmeli \& Schaubroeck, 2007, p. 37). Employees believe that when their leader expects them to be creative, it reflects the leader's confidence in their competencies (Tierney \& Farmer, 2004). As a result, they also expect that the leader will provide the necessary organizational resources in exhibiting creativity (Scott \& Bruce, 1994). It leads to the conclusion that leader creativity expectations have a very strong relationship with creative performance (Whiteley, Sy, \& Johnson, 2012).

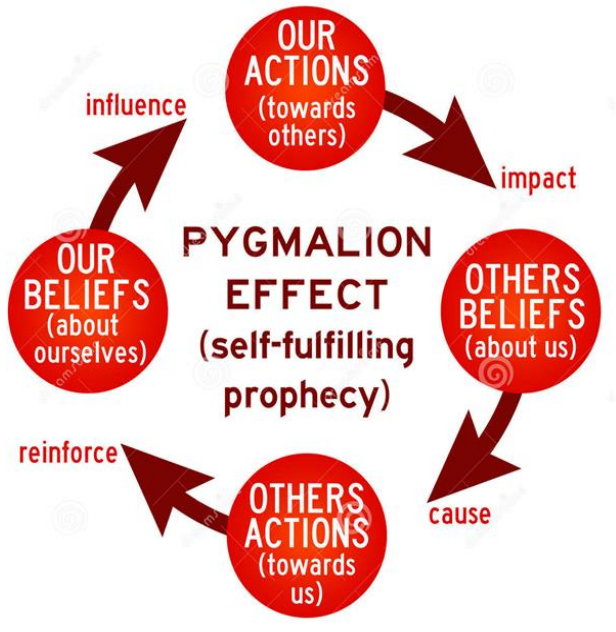

Figure 3 - Pygmalion Effect 


\section{The Relationship between Leader Creativity Expectations and Creative Performance}

Undoubtedly, setting expectations for subordinates in such a manner that they could achieve set goals is a challenging task (Amabile \& Gryskiewicz, 1987). Leader creativity expectations serve as a very strong motivational force among employees for exhibiting creativity (Carmeli \& Schaubroeck, 2007; Locke \& Latham, 1990; Redmond, Mumford, \& Teach, 1993). In response to leader's creativity expectations, followers also develop their expectations from their leader as well in terms of the availability of mentoring, appreciation, friendliness, and dependency (Xu, Huang, Lam, \& Miao, 2012).

Very little empirical evidence is known to date about the application of Pygmalion effect on creative performance with minor exceptions such as Adil, Khan, Khan, \& Qureshi, 2018; Carmeli \& Schaubroeck, 2007; Eden, 1992; Jiang \& Gu, 2017; Qu et al., 2015; Scott \& Bruce, 1994; Tierney \& Farmer, 2004; Whiteley et al., 2012. Nevertheless, Dong, Bartol, Zhang, and Li (2017) have recently advised to further ascertain the relationship between leader creativity expectations and creative performance. In short, it is argued that leaders should effectively communicate their creativity expectations with their followers (Shalley \& Gilson, 2004). Therefore, we propose the following:

Proposition 1: There will be a positive relationship between leader creativity expectations and creative performance.

\section{Intrinsic Motivation and Herzberg's Two-Factor Theory}

Herzberg's two-factor theory of motivation is classified as a content theory (Fisher, 2009). In 1959, Frederick Irving Herzberg coined this theory of motivation which is also termed as known as Herzberg's motivationhygiene theory or dual-factor theory or bi-factor theory (Herzberg, 1959; Herzberg, Mausner, \& Snyderman, 1959). Based on over 200 interviews with general managers and accounting professionals in manufacturing firms of Pittsburg, Pennsylvania about what satisfied or dissatisfied them in their job, two sets of factors were emerged: 'hygiene' and 'motivator' factors.

Motivators comprise of factors which a manager can use to encourage his subordinates for better job performance whereas, managers should alleviate the repercussion of hygiene factors which may cause job dissatisfaction (Herzberg, Mausner, \& Snyderman, 2005; Sledge, Miles, \& Coppage, 2008). Figure 4 depicts different factors affecting job attitudes as reported in 12 investigations (Herzberg, 2003).

Leader creativity expectations may be conceptualized as a hygiene factor because expectations do not generally present as an integral component of one's job description. Rather, the expectations are the organizational (or contextual) factor which if present may motivate someone, however, will surely disappoint the person if not present in the job. In other words, it has been argued that employees are less likely to exhibit creativity in their jobs when they have established a strong feeling that they are not expected to perform creativity or even their job does not require them to be creative. Consequently, it leads to employee job dissatisfaction.

So far we have argued that leader creativity expectations will have a positive relationship with creative performance. Moreover, we also propose that there will be an indirect relationship between leader creativity expectations and creative performance through intrinsic motivation. The componential theory of creativity holds that intrinsic motivation is one of the three key components of employee creative performance (Amabile, 1983; Csikszentmihalyi, 1996) though, it depends on various boundary conditions (Meng, Tan, \& $\mathrm{Li}, 2017)$. 


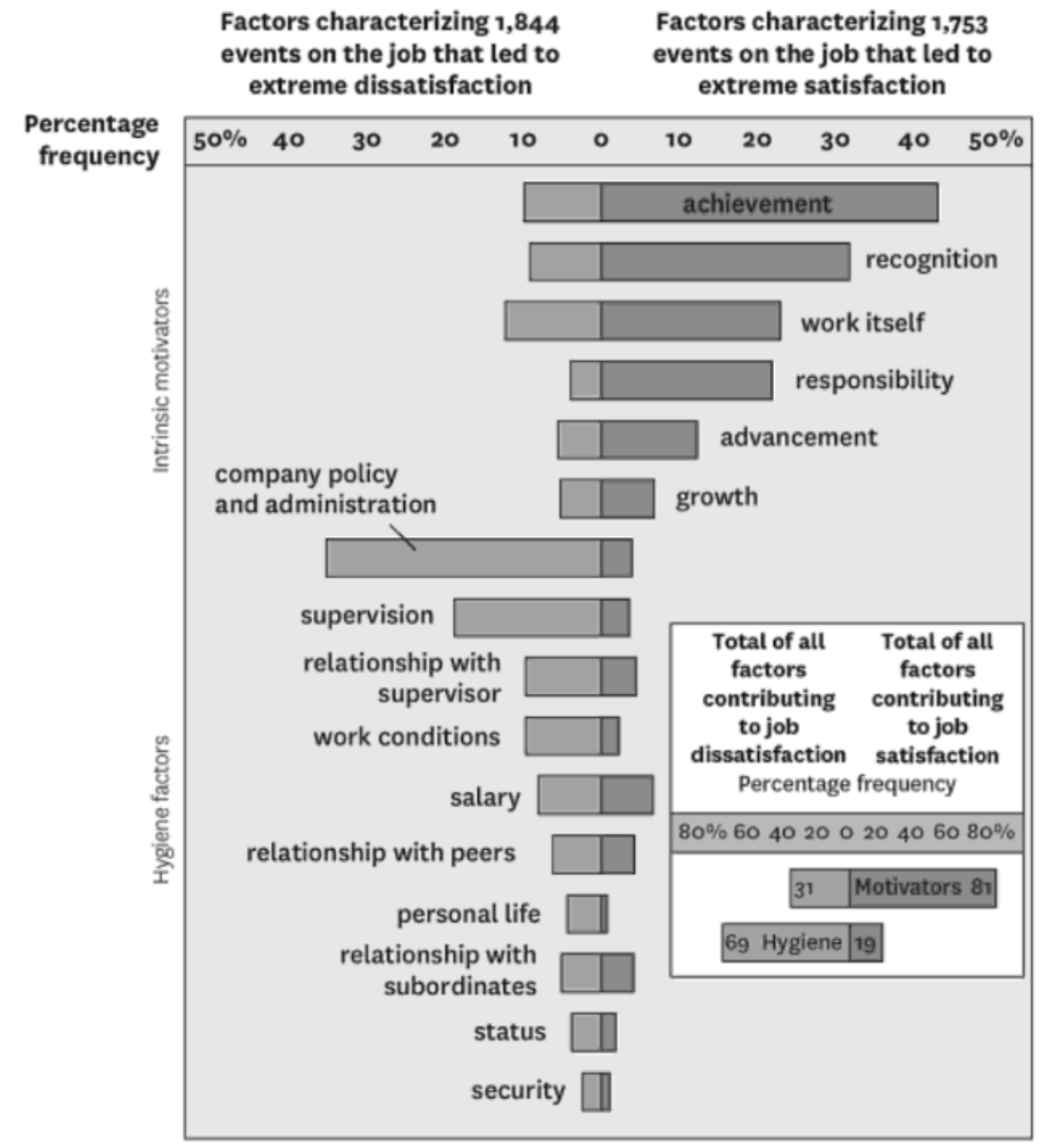

Figure 4 - Factors Affecting Job Attitudes As Reported In 12 Investigations

Source: Adapted from Herzberg (2003, p. 90)

Numerous literature (e.g. Amabile, Hennessey, \& Tighe, 1994; Amabile \& Mueller, 2008; Carmeli, ReiterPalmon, \& Ziv, 2010; Shalley, Zhou, \& Oldham, 2004) and some recent empirical evidence (e.g. Hannam \& Narayan, 2015; Hur et al., 2016; Muñoz-Pascual, \& Galende, 2017) have suggested that intrinsic motivation is a mediating construct between different variables and creative performance. Therefore, we propose the following:

Proposition 2: Intrinsic motivation will mediate the relationship between leader creativity expectations and creative performance.

\section{Measurement of Creative Performance}

Creative performance has been measured in both objectives as well as in a subjective manner. In fact, adherents of objectives measurement of creativity believe that creativity is output in the form of a product, 
patent, license or any other form of intellectual property. Moreover, in a number of studies, a supervisor has rated the creative performance of his/her subordinates e.g. George and Zhou (2001); Oldham and Cummings (1996); Tierney and Farmer (2011) etc.

In contrast, we propose that creative performance may also be measured in a subjective way, particularly selfrated by the individual whose performance is being measured because "...they are the ones who are aware of the subtle things they do in their jobs that make them creative" (Shalley, Gilson, \& Blum, 2009, p. 495). Moreover, Liao, Liu, and Loi (2010) argued that "supervisors' subjective ratings of subordinates' creativity may be biased due to a variety of intentional and inadvertent factors such as demographic characteristics, supervisory liking, and halo effect" (p. 1097) though, "...more work is now needed to further examine the effects of employees' self-views on their creativity" (Shalley et al., 2004, p. 946).

Past studies have used a self-reported scale for measuring employee creative performance e.g. Aleksić, Černe, Dysvik, and Škerlavaj (2016); Dahmen-Wassenberg, Kämmerle, Unterrainer, and Fink (2016); Kemmelmeier and Walton (2016); Laguía, Moriano, and Gorgievski (2019) etc. Besides, some meta-analyses have also provided a systematic review of self-report creative performance e.g. Silvia, Wigert, Reiter-Palmon, and Kaufman (2012) etc.

\section{Measurement of Leader Creativity Expectations}

A single-item (e.g. Scott \& Bruce, 1994), as well as a multi-item scale (e.g. Carmeli \& Schaubroeck, 2007), have been used in the creativity literature to quantitatively measure leader creativity expectations. Furthermore, Tierney \& Farmer (2004) used Wanous, Reichers, and Hudy (1997) technique to address the convergent validity issues of a single-item scale. Although some recent studies (e.g. Jiang \& Gu, 2017); Zhao \& Guo, 2019) have used this scale and reported acceptable psychometric properties of the scale, we suggest that upcoming studies should use Carmeli and Schaubroeck (2007) four-item scale because of it better accounts for measurement error. Moreover, either a five-point Likert type ordinal measuring scale or 7 points numerical scale for interval level of measurement may be used for hypothesis testing.

\section{Conclusion}

Creative performance has increasingly gained its momentum in the 21st century. Authors are in search of new insights by theorizing its direct and/or indirect relationship with numerous variables, inter alia, transformational leadership, abusive supervision, ambidextrous leadership, workplace ostracism, objective underemployment, emotional and cultural intelligence, leader humility, information literacy, career and performance orientation etc. Drawing upon the principle of Pygmalion effect, Herzberg's two-factor theory, and componential theory of creativity, we suggested two proposition with a review to establish a direct relationship between leader creativity expectations and creative performance as well as an indirect relationship with intrinsic motivation. It was argued that a better understanding of leader creativity expectations in stimulating employee creative performance should lead to better outcomes for both organizations and individuals as well as it provides directions for future studies too.

\section{References}

Adil, M. S., Khan, M. N., Khan, I., \& Qureshi, M. A. (2018). Impact of leader creativity expectations on employee creativity: Assessing the mediating and moderating role of creative self-efficacy. International Journal of Management Practice, 11(2), 171-189.

Aleksić, D., Černe, M., Dysvik, A., \& Škerlavaj, M. (2016). I want to be creative, but... preference for creativity, perceived clear outcome goals, work enjoyment, and creative performance. European Journal of Work and Organizational Psychology, 25(3), 363-383. 
Amabile, T. M. (1983). Social psychology of creativity: A componential conceptualization. Journal of Personality and Social Psychology, 45(2), 357-376.

Amabile, T. M. (1988). A model of creativity and innovation in organizations. In B. M. Staw, \& L. L. Cummings (Eds.), Research in organizational behavior (Vol. 10, pp. 123-167). Greenwich, CT: JAI Press.

Amabile, T. M. (1998). How to kill creativity? Harvard Business Review, 76(5), 76-87.

Amabile, T. M., \& Gryskiewicz, S. (1987). Creativity in the R\&D laboratory (Technical Report No. 30). Greensboro, NC: Center for Creative Leadership.

Amabile, T. M., Hill, K. G., Hennessey, B. A., \& Tighe, E. (1994). The work preference inventory: Assessing intrinsic and extrinsic motivational orientations. Journal of Personality and Social Psychology, 66(5), 950-967.

Amabile, T. M., \& Mueller, J. S. (2008). Studying creativity, its processes, and its antecedents: An exploration of the componential theory of creativity. In J. Zhou, \& C. E. Shalley (Eds.), Handbook of organizational creativity (pp. 33-64). New York, NY: Lawrence Erlbaum.

Amabile, T. M., \& Pratt, M. G. (2016). The dynamic componential model of creativity and innovation in organizations: Making progress, making meaning. Research in Organizational Behavior, 36, 157-183.

Anderson, J. V. (1992). Weirder than fiction: The reality and myths of creativity. Academy of Management Executive, 6(4), 40-47.

Carmeli, A., Reiter-Palmon, R., \& Ziv, E. (2010). Inclusive leadership and employee involvement in creative tasks in the workplace: The mediating role of psychological safety. Creativity Research Journal, 22(3), $250-260$.

Carmeli, A., \& Schaubroeck, J. (2007). The influence of leaders' and other referents' normative expectations on individual involvement in creative work. The Leadership Quarterly, 18(1), 35-48.

Carr, A. (2010). The most important leadership quality for CEOs? Creativity. Fastcompany.com. Retrieved from https://www.champlain.edu/Documents/core_division/fastcompany_5_10.pdf

Csikszentmihalyi, M. (1996). Creativity: Flow and the psychology of discovery and invention. New York, NY: Harper Collins Publishers.

Dahmen-Wassenberg, P., Kämmerle, M., Unterrainer, H-F., \& Fink, A. (2016). The relation between different facets of creativity and the dark side of personality. Creativity Research Journal, 28(1), 60-66.

D'Aveni, R., \& Gunther, R. (1994). Hypercompetition: Managing the dynamics of strategic maneuvering. New York: Free Press.

Dong, Y., Bartol, K. M., Zhang, Z. X., \& Li, C. (2017). Enhancing employee creativity via individual skill development and team knowledge sharing: Influences of dual-focused transformational leadership. Journal of Organizational Behavior, 38(3), 439-458.

Drazin, R., Glynn, M. A., \& Kazanjian, R. K. (1999). Multilevel theorizing about creativity in organizations: A sense making perspective. Academy of Management Review, 24(2), 286-307.

Eden, D. (1984). Self-fulfilling prophecy as a management tool: Harnessing Pygmalion. Academy of Management Review, 9(1), 64-73. 
Eden, D. (1992). Leadership and expectations: Pygmalion effects and other self-fulfilling prophecies in organizations. The Leadership Quarterly, 3(4), 271-305.

Eden, D., Geller, D., Gewirtz, A., Gordon-Terner, R., Inbar, I., Liberman, M., Pass, Y., Salomon, I., \& Shalit, M. (2000). Implanting Pygmalion leadership style through workshop training: Seven field experiments. The Leadership Quarterly, 11(2), 171-210.

Feist, G. J. (1998). A meta-analysis of the impact of personality on scientific and artistic creativity. Personality and Social Psychological Review, 2, 290-309.

Fisher, E. A. (2009). Motivation and leadership in social work management: A review of theories and related studies. Administration in Social Work, 33(4), 347-367.

George, J. M., \& Zhou, J. (2001). When openness to experience and conscientiousness are related to creative behavior: An interactional approach. Journal of Applied Psychology, 86(3), 513-524.

Guilford, J. P. (1950). Creativity. American Psychologist, 5(9), 444-454.

Hannam, K., \& Narayan, A. (2015). Intrinsic motivation, organizational justice, and creativity. Creativity Research Journal, 27(2), 214-224.

Herzberg, F. (1959). The motivation to work. New York: John Wiley and Sons.

Herzberg, F. (2003). One more time: How do you motivate employees? Harvard Business Review, 81(1), 8796.

Herzberg, F., Mausner, B., \& Snyderman, B. B. (1959). The motivation to work (2nd edition). New York: John Wiley and Sons.

Herzberg, F., Mausner, B., \& Snyderman, B. B. (2005). The motivation to work. New Jersey: Transaction Publishers.

Hur, W. M., Moon, T., \& Jun, J. K. (2016). The effect of workplace incivility on service employee creativity: The mediating role of emotional exhaustion and intrinsic motivation. Journal of Services Marketing, 30(3), 302-315.

Jiang, W., \& Gu, Q. (2017). Leader creativity expectations motivate employee creativity: A moderated mediation examination. The International Journal of Human Resource Management, 28(5), 724-749.

Kemmelmeier, M., \& Walton, A. P. (2016). Creativity in men and women: Threat, other-interest, and selfassessment. Creativity Research Journal, 28(1), 78-88.

Laguía, A., Moriano, J. A., \& Gorgievski, M. J. (2019). A psychosocial study of self-perceived creativity and entrepreneurial intentions in a sample of university students. Thinking Skills and Creativity, 31, 44-57.

Liao, H., Liu, D., \& Loi, R. (2010). Looking at both sides of the social exchange coin: A social cognitive perspective on the joint effects of relationship quality and differentiation on creativity. Academy of Management Journal, 53(5), 1090-1109.

Locke, E. A., \& Latham, G. P. (1990). A theory of goal setting and task performance. Englewood Cliffs: Prentice-Hall.

Ma, H. H. (2009). The effect size of variables associated with creativity: A meta-analysis. Creativity Research Journal, 21(1), 30-42. 
Mainemelis, C. (2001). When the muse takes it all: A model for the experience of timelessness in organizations. Academy of Management Review, 26(4), 548-565.

Meng, Y., Tan, J., \& Li, J. (2017). Abusive supervision by academic supervisors and postgraduate research students' creativity: The mediating role of leader-member exchange and intrinsic motivation. International Journal of Leadership in Education, 20(5), 605-617.

Morgan, D. N. (1953). Creativity today: A constructive analytic review of certain philosophical and psychological Work. The Journal of Aesthetics and Art Criticism, 12(1), 1-24.

Muñoz-Pascual, L., \& Galende, J. (2017). The impact of knowledge and motivation management on creativity: Employees of innovative Spanish companies. Employee Relations, 39(5), 732-752.

Ochse, R. (1990). Before the gates of excellence: The determinants of creative genius. Cambridge, UK: Cambridge University Press.

Oldham, G. R., \& Cummings, A. (1996). Employee creativity: Personal and contextual factors at work. Academy of Management Journal, 39(3), 607-634.

Perry-Smith, J. E., \& Shalley, C. E. (2003). The social side of creativity: A static and dynamic social network perspective. Academy of Management Review, 28(1), 89-106.

Policastro, E. (1995). Creative intuition: An integrative review. Creativity Research Journal, 8(2), 99-113.

Qu, R., Janssen, O., \& Shi, K. (2015). Leader-member exchange and follower creativity: the moderating roles of leader and follower expectations for creativity. The International Journal of Human Resource Management, 28(4), 603-626.

Redmond, M. R., Mumford, M. D., \& Teach, R. (1993). Putting creativity to work: Effects of leader behavior on subordinate creativity. Organizational Behavior and Human Decision Processes, 55, 120-151.

Runco, M. A., \& Acar, S. (2012). Divergent thinking as an indicator of creative potential. Creativity Research Journal, 24(1), 66-75.

Sadler-Smith, E. (2015). Wallas' four-stage model of the creative process: More than meets the eye?. Creativity Research Journal, 27(4), 342-352.

Scott, S. G., \& Bruce, R. A. (1994). Determinants of innovative behavior: A path model of individual innovation in the workplace. Academy of Management Journal, 37, 580-607.

Shalley, C. E., \& Gilson, L. L. (2004). What leaders need to know: A review of social and contextual factors that can foster or hinder creativity. The Leadership Quarterly, 15(1), 33-53.

Shalley, C. E., Gilson, L. L., \& Blum, T. C. (2009). Interactive effects of growth need strength, work context, and job complexity on self-reported creative performance. Academy of Management Journal, 52(3), 489-505.

Shalley, C. E., Zhou, J., \& Oldham, G. R. (2004). The effects of personal and contextual characteristics on creativity: Where should we go from here? Journal of Management, 30(6), 933-958.

Silvia, P. J., Wigert, B., Reiter-Palmon, R., \& Kaufman, J. C. (2012). Assessing creativity with self-report scales: A review and empirical evaluation. Psychology of Aesthetics, Creativity, and the Arts, 6(1), 1934. 
Sledge, S., Miles, A. K., \& Coppage, S. (2008). What role does culture play? A look at motivation and job satisfaction among hotel workers in Brazil. The International Journal of Human Resource Management, 19(9), 1667-1682.

Sternberg, R. J., \& Lubart, T. I. (1999). The concept of creativity: Prospects and paradigms. In R. J. Sternberg (Ed.), Creativity research handbook (pp. 3-15). New York: Cambridge University Press.

Tierney, P., \& Farmer, S. M. (2004). The Pygmalion process and employee creativity. Journal of Management, 30, 413-432.

Tierney, P., \& Farmer, S. M. (2011). Creative self-efficacy development and creative performance over time. Journal of Applied Psychology, 96(2), 277-293.

Unsworth, K. (2001). Unpacking creativity. Academy of Management Review, 26(2), 289-297.

Wallas, G. (1926). The art of thought. London, UK: Jonathan Cape.

Wanous, J. P., Reichers, A. E., \& Hudy, M. J. (1997). Overall job satisfaction: How good are single-item measures?. Journal of Applied Psychology, 82(2), 247-252.

Whiteley, P., Sy, T., \& Johnson, S. K. (2012). Leaders' conceptions of followers: Implications for naturally occurring Pygmalion effects. The Leadership Quarterly, 23(5), 822-834.

Xu, E., Huang, X., Lam, C. K., \& Miao, Q. (2012). Abusive supervision and work behaviors: The mediating role of LMX. Journal of Organizational Behavior, 33(4), 531-543.

Zhao, H., \& Guo, L. (2019). The trickle-down effects of creative work involvement: The joint moderating effects of proactive personality and leader creativity expectations. Personality and Individual Differences [accepted, in press]. 